\title{
A Review on Systematic Investigation of Leucocytes Identification and Classification Techniques for Microscopic Blood Smear
}

\author{
Mr. Pranav More ${ }^{\mathrm{a}, 1}$, Prof. Dr. Rekha Sugandhi ${ }^{\mathrm{b}}$ \\ ${ }^{a}$ Dept of CSE, MIT School of Engineering, MIT ADT University Pune, \\ Maharashtra, India \\ ${ }^{b}$ Dept of IT, MIT School of Engineering, MIT ADT University Pune, Maharashtra, \\ India
}

\begin{abstract}
Healthcare services are an important part of human beings and healthcare services are changing with new and innovative technologies. In recent day's healthcare sector performing very crucial role in metamorphose of traditional health services to e-health technologies. This proposal provides an error-free and improved technology-based blood analysis service for the identification of leucocytes in blood samples of humans. Leucocytes play a vital and important character in human immune systems. This system helps to protect the body from suffering from leukemia. Leukemia, a blood cancer, nowadays is commonly found in all age persons. Leukemia is a type of disease and image processing techniques and algorithms can play a crucial role in disease diagnostic methodology. Identification of leukocytes in blood smear provides important information to pathologist as well as doctors to analyze and predicts different types of diseases, such as cancer. However, this analysis is critical and major complexities which results in errors and also takes a lot of time for analysis. Most of the time, the laboratory practitioners and doctors are interested only in leucocytes in blood smear. Medical image processing techniques strongly supports in their critical diagnosis and better results.
\end{abstract}

Keywords. leukemia, cytoplasm, leucocytes, hematic disease, nucleus

\section{Introduction}

The image processing and analysis is an important and emerging research area which has attracted a significant amount of interest from academic to industrial communities since last few years. Medical image recognition and processing applications widely used in the health domain for better results. The digitized and computerized system plays a vital role in various lines of research such as radioactive pharmaceuticals, $\mathrm{x}$ rays (CT scans), magnetism (MRI), sound (ultrasound) and light (endoscopy, OCT), etc. The analysis of Leukocytes used in the clinical investigation of different diseases with

1 Mr. Pranav More, Dept of CSE, MIT School of Engineering, MIT ADT University Pune Email : pranavmore2530@gmail.com 
the help of digitized medical images and extracting important and accurate information. This extracted meaningful information is really valuable and useful for lab practitioners. In recent years, medical image analysis has helped to hematologists to analyze the different components of blood such as cells.

The analysis of different blood components leads to good quality, accurate, health standard, and remote disease diagnosis systems. Clinical analysis of blood samples to perform CBC (Complete Blood Count) is mandatory these days to go for any conclusion regarding the health diseases. In most of the cases, lab practitioners and doctors are responsive in white blood cells. Medical image processing techniques can promote the systematic use of health parameters in IT. This also tells about the secure sharing of human health information among health care professionals and practitioners.

Health professionals can check disease like leukemia and performs the analysis on detected components and condition of the cells like WBC. This digitization mainly segments the detected cells into two important elements such as nucleus and cytoplasm. This cell segmentation is performed using a proposed cell segmentation framework. The identification and classification of blood cancer leukemia majorly consist of several digital images processing algorithms like medical image acquisition, medical image segmentation, and feature extraction of the blood sample, feature selection, and classification of cells.

In this scenario, there are some limitations in data extraction from blood cell components due to large variations in cell size, shape of a cell, connected edges of cells, and cell position. If illumination is not balanced between the cell properties, the image color component contrast between blood cell edges and the cell background get changed based on the situation at the time of capturing process. The major important goal of this is to segment the cytoplasm and cell nucleuses using image digitization which we implemented and tested using medical image processing. In healthcare industries, medical image processing techniques use increased very fast in the recent few years. Figure 1 in this analysis, hematologists can conduct analysis on blood images and automatically process blood samples for the initial assumption of detecting the various diseases.

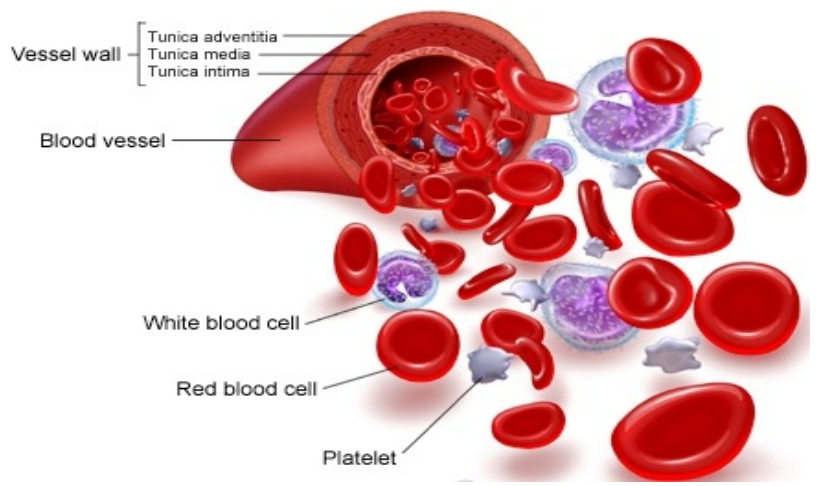

Figure 1. Types of blood cells in the human body 
This methodology is used to identify the blood cells and counts the total numbers of white blood cells in the human body with higher accuracy and automated approach. This also provides complete and clear information on the nucleus versus cytoplasm ratio. This helps in the identification and classification of different kinds of white blood cells by using the internal component such as monocyte, eosinophil, basophil, neutrophil, and lymphocyte. Figure 2 in this research, a proposed methodology consists of different methods for segmentation and extraction which combines together for cell kernel and extracted cytoplasm.
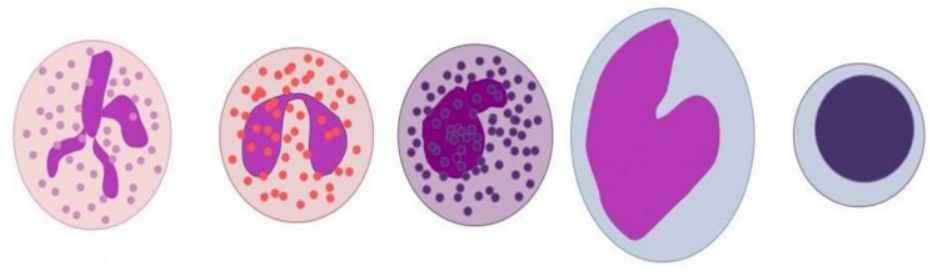

\section{neutrophil}

\section{eosinophil basophil monocyte lymphocyte}

Figure 2. Types of White Blood Cells

\section{Motivation}

This research is very important to apply in medical field digital image processing for medical image examination and diagnosis. The major purpose of this research is to develop a framework to early diagnosing and classification of acute leukemia. Generally this can be done with the help of cell morphology, and classifies into (AML) Acute Meyloid Leukemia or (AAL) Acute Lymphoblastic Leukemia. The peripheral blood examination has been done for this research for following reasons including:

A. The blood malignant growth smear location measure is inspected dependent on the magnifying instrument morphological investigation of fringe blood slides. Further research center tests will be done dependent on the result of the underlying analysis.

B. The PB is typically utilized for an intermittent treatment assessment, since it is a lot simpler, more conservative, and less excruciating to get blood from the vein as opposed to from the BM.

\section{Literature Review}

AAL or AML Leukemia will be treated as a blood cancer. This will treated as most dangerous disease which influences the blood cells including White Blood Cells (WBCs). This will lead to casualty among people in many of the countries [15]. Human blood is a combination of billions of different cells in a super liquid form. Blood contains mainly three broad types of blood cells namely Erythrocytes commonly named as Red Blood Cells, Leukocytes commonly named as White Blood Cells, and 
some platelets. Erythrocytes are majorly responsible for oxygen transportation; White Blood Cells perform fighting with infections and platelets are important for blood clotting. As per the statistics by the ACS (American Cancer Society), blood cancer is treated as a common cancer type, especially in children [16]. In the United States on average 29,000 cases in adults and in children near about 2000 cases are diagnosed.

Report by Agency of International Research on Cancer:

In 2016, one important report was released by the IARC and states that the frequency of children cancer higher than previously. This report completely depends on more than 90 cancer registries in 65 countries during the period 2001-2010. This indicates that near about 250,000 cases of blood cancers were diagnosed in teens and children under the age of 19. As per the report given by IARC on Cancer, [14] the following statistics in Figure 3, mentioned that there were approximately 80,000 deaths in a year from childhood cancer in the world.

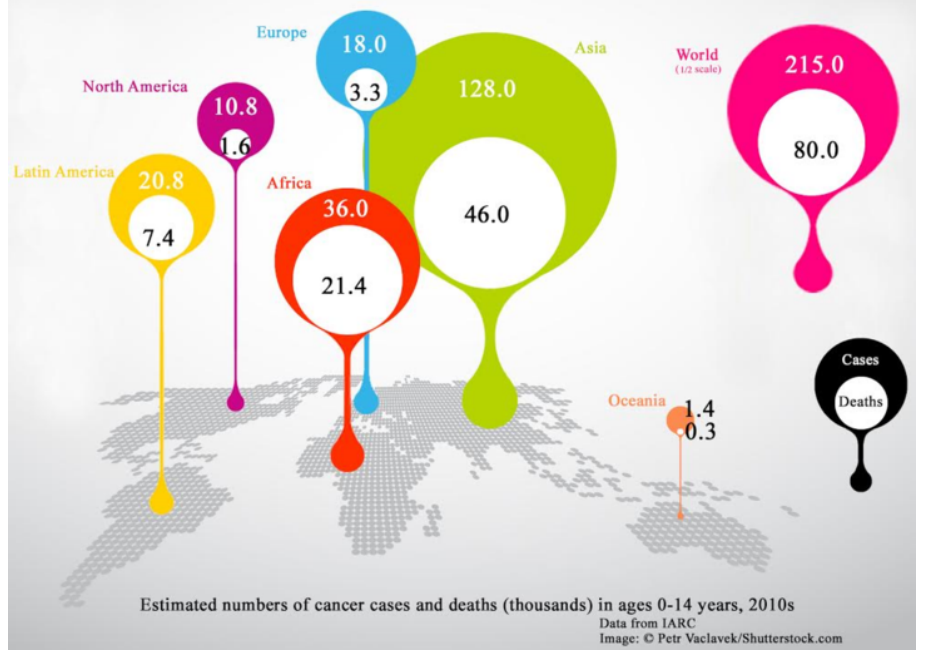

Figure 3. Statistics by International Agency for Research on Cancer-2016 [14]

Statistics by the American Cancer Society:

As per the analysis by the (ACS) Cancer Society America, leukemia is treated as common types of cancer, majorly found in children. Every year in United States near about 29,000 adults and near about 2000 new blood cancer cases are found \& diagnosed. Generally, leukemia shows an impact on people in all age groups. In $85 \%$ of children, leukemia can be found in acute type. On the basis of analysis done by ACS, it has been proved that due to leukemia there is leading death ratio in children aged 1 to 14 years old [16]. According to the [17], the following graph in Figure 4, gives the total statistics of United States of cancer found in children from their birth to 15 years old. Figure 4 explains about the childhood cancer and affected areas of human body. Cancer affect the human body parts as per the as per the level and depth of a cancer.

\section{Statistics of National Cancer Registry}

The National Cancer Registry report distributed in 2008 [24], it has been demonstrated that malignancy in Malaysia is as per the human sex. In men, significantly discovered 
the tumors are (incessant to least continuous): huge entrails, lung, nasopharyngeal malignancy, prostate organ, leukemia, lymphoma, stomach, liver, bladder, and other skin diseases. (Refer to Figure 5)

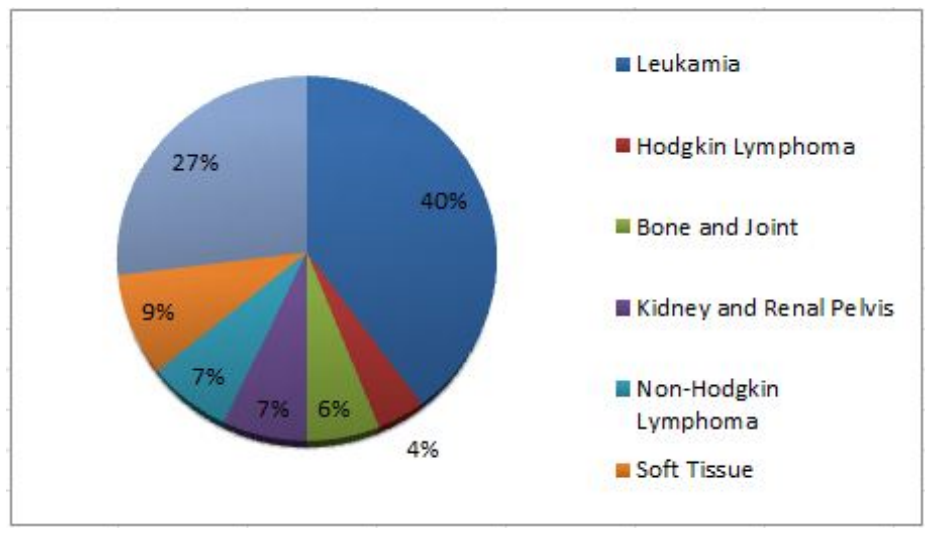

Figure 4. Analysis of US of Childhood Cancer

\section{Statistics of National Cancer Registry}

The National Cancer Registry report distributed in 2008 [24], it has been demonstrated that malignancy in Malaysia is as per the human sex. In men, significantly discovered the tumors are (incessant to least continuous): huge entrails, lung, nasopharyngeal malignancy, prostate organ, leukemia, lymphoma, stomach, liver, bladder, and other skin diseases. (Refer to Figure 5)

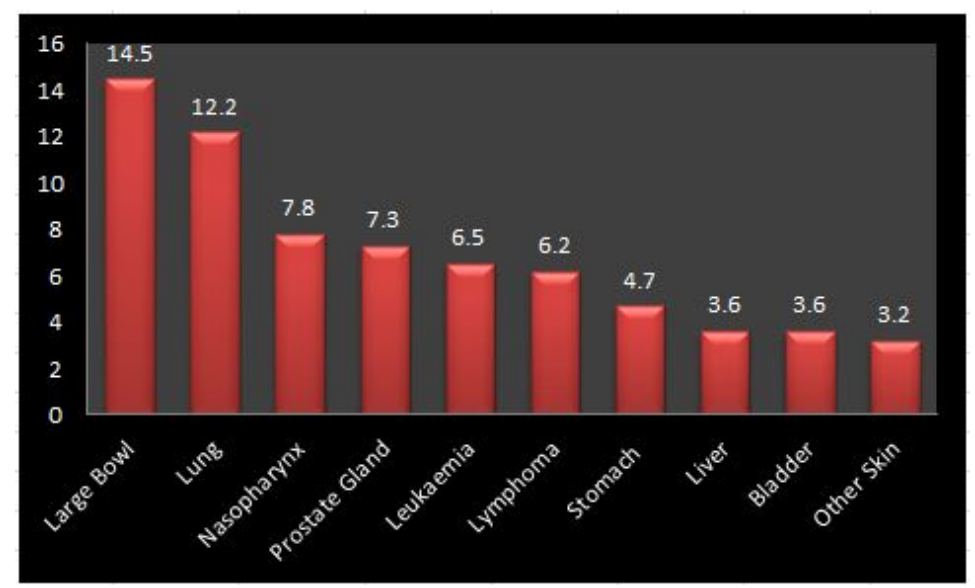

Figure 5. General category of Cancer in Malaysia in Male

The National Cancer Registry report distributed in 2008 [24], it has been demonstrated that in females, the commonest malignancies are (from generally successive to least incessant): bosom, cervix, enormous inside, ovary, leukemia, lung, lymphoma, corpus uteri, thyroid organ, and stomach. (Refer to Figure 6) 


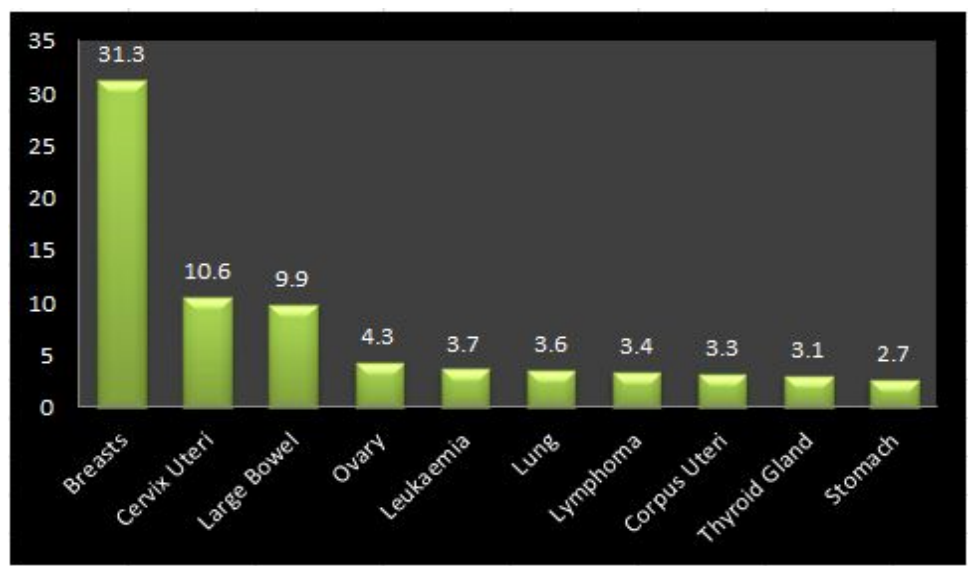

Figure 6. General category of Cancer in Malaysia in Female

\section{Classification Methods}

The literature review process started with studying the general challenges of Image processing such as Noise in segmented images, Cytoplasm shape, Background separation, Cell overlapping, Feature extraction, and Classification. Also how to maintain the sensitivity and specificity by using Multilevel Threshold-based image segmentation and how to increase the accuracy of classification.

Yampri proposed the use of green colour components for automatic thresholding between cytoplasm and nucleus for good contrast [08]. The available noise in the image is eliminated using the standard morphological operation process and the nucleus and cells are segmented using active contours. In some cases, most of the WBCs can have more number of nuclei in a cell, which results in decreasing of accuracy.

Some of the image processing operators analyse the boundary connection of the segmented nucleus using Watershed transformation. During this process, some series of morphological operations are performed structurally and cell size distribution data is used to distinguish the red blood cells and background of cytoplasm. A few restrictions are experienced when the states of the cytoplasm are not roundabout and the sizes change as indicated by the kinds of WBCs. [02]

In some proposed mechanism colour replacement used o find out neighbour contour cell using modified fuzzy c-mean clustering [09] technique. This approach can be cluster-based and the modification of data values is based on iteration. To test the images manual cropping of an image is required and an overall performance with other adaptive methods is evaluated.

Shift clustering [10] also used for leukocyte identification from blood images. This research used merging rules-based for mean-shift clustering and removing of boundary rules. Sholeh [11] proposed an algorithm for white blood cell image segmentation and enhancements of properties. Some operations related to morphology were used to remove unwanted noise and platelets from blood smear images. To maintain the structure of the identified cell, the opening of cell and cell closing operations were executed. Blue channel is used for the segmentation of WBC and finally, all five types 
of WBCs were extracted, counted, and classified after analysis of cells. In the last step leukocytes counting is performed of segmented image and some features extraction properties such as minor axis length, major axis length, and average. Otsu segmentation an alternative methodology that can be applied directly for an image with the help of before segmentation of WBCs enhancement on blood samples [12]. Then, some of the morphological operations were used for eliminating undesired objects. Finally filling of holes can be performed.

Prinyakupt and Pluempitiwiriyawej [10] proposed the use of image thresholding and morphology for blood cell segmentation. Morphology is the process of complex mathematical computation which applies subtraction as well as addition on blood sample image. This will separate RBC, White blood cells and Platelets from the blood component. Segmentation was responsible to partition the image into two areas such as background and foreground by using an optimal threshold value.

Ravikumar [14] proposed a comprehensive investigation of two methodologies known as fast relevance vector machine (FRVM) and standard extreme learning machine (ELM) distribution technique used for segmentation. After comparing these two classification techniques identified that it performs well in local computation of maxima. In general, ELM is not satisfactory concerning performance than FRVM.

Table 1 describes the work done by various researchers in the field of medical image processing. In this table various technologies and methodologies are explained by the authors with respect to their accuracy and other remarks. Table describes the classification methods with respect to their works and methods. This table gives the idea about the work done in this field and results achieved by the researchers. Different classification methods are explained here for understanding and getting idea about the work done in this field.

Table 1. Study of Classification Techniques for Leukocyte Classification

\begin{tabular}{|c|c|c|c|}
\hline Authors and Year & Work done & $\begin{array}{c}\text { Technologies/ Algorithms } \\
\text { used }\end{array}$ & $\begin{array}{l}\text { Accuracy/ } \\
\text { Remark }\end{array}$ \\
\hline $\begin{array}{l}\text { Nilanjan Ray, } 2010 \\
{[25]}\end{array}$ & $\begin{array}{l}\text { Formulation for Parametric } \\
\text { Curve Fitting }\end{array}$ & $\begin{array}{l}\text { Curve fixing, Curved } \\
\text { programming, leukocyte } \\
\text { discovery, oval fixing }\end{array}$ & $\begin{array}{l}\text { Can be extended } \\
\text { for feature } \\
\text { correspondent. }\end{array}$ \\
\hline $\begin{array}{l}\text { Singh, Gautam, } \\
\text { Bhadauria, Raman, } \\
2016[26]\end{array}$ & $\begin{array}{l}\text { Leukocytes Classification } \\
\text { with the help of Naïve Bayes } \\
\text { Classifier and Morphology } \\
\text { Features }\end{array}$ & $\begin{array}{l}\text { Otsu thresholding for } \\
\text { segmentation, mathematical } \\
\text { morphing, Naïve Bayes } \\
\text { classification }\end{array}$ & $\begin{array}{l}80.88 \% \text { accurate } \\
\text { Average } \\
\text { processing } 22 \mathrm{~s} .\end{array}$ \\
\hline $\begin{array}{l}\text { Doric, Irena, } \\
\text { Novoselnik, Grbic, } \\
2018 \text { [27] }\end{array}$ & $\begin{array}{l}\text { Convolutional Neural } \\
\text { Network used for } \\
\text { Identification and detection of } \\
\text { cells }\end{array}$ & $\begin{array}{l}\text { Segmentation and } \\
\text { classification in } 5 \text { categories } \\
\text { using }(\mathrm{CNN}) \text { Convolutional } \\
\text { Neural Network. }\end{array}$ & $81.11 \%$ accurate. \\
\hline $\begin{array}{l}\text { Mlndhu, Dhiravida, } \\
\text { Muthu, } 2018 \text { [28] }\end{array}$ & $\begin{array}{l}\text { Convolutional Sparse } \\
\text { Dictionary Learning used for } \\
\text { Cell Discovery and Cell } \\
\text { calculation }\end{array}$ & $\begin{array}{l}\text { Holographic lenses free cell } \\
\text { image in convolutional } \\
\text { sparse dictionary learning }\end{array}$ & $\begin{array}{l}\text { Checked zone } \\
\text { has been } \\
\text { recognized, } \\
\text { distinguished }\end{array}$ \\
\hline $\begin{array}{l}\text { Harvindra } \\
\text { Bhadauria, Anjali } \\
\text { Gautam, 2014 [29] }\end{array}$ & $\begin{array}{l}\text { Morphological Features are } \\
\text { used for classification }\end{array}$ & $\begin{array}{l}\text { Otsu's thresholding, } \\
\text { morphing, classification of } \\
\text { nucleus }\end{array}$ & $\begin{array}{l}\text { Accurate } \\
\text { classification of } \\
\text { wbcs }\end{array}$ \\
\hline $\begin{array}{l}\text { Muhammad, Khan, } \\
\text { Shoaib, Ali, } \\
\text { Sajjad,2016 [30] }\end{array}$ & $\begin{array}{l}\text { Classification \& Segmentation } \\
\text { using k- means algorithm, } \\
\text { morphing, SVM for } \\
\text { classification }\end{array}$ & $\begin{array}{l}\text { Segmentation of nuclei, } \\
\text { classification of wbcs }\end{array}$ & $\begin{array}{c}\text { Accuracy } \\
\text { higher than linear } \\
\text { and naive Bayes } \\
\text { classifiers. }\end{array}$ \\
\hline
\end{tabular}




\begin{tabular}{|l|l|l|c|}
$\begin{array}{l}\text { Lalit Mohan Saini, } \\
\text { Shubham Manik, } \\
\text { Nikhil Vadera, } \\
2016 \text { [31] }\end{array}$ & $\begin{array}{l}\text { Artificial Neural Network is } \\
\text { used for counting of cells as } \\
\text { well as classification. }\end{array}$ & $\begin{array}{l}\text { Classification performed } \\
\text { using ann. Finding of } \\
\text { Intensity maxima for Nucleus } \\
\text { Enhancement }\end{array}$ & $\begin{array}{c}\text { Accuracy - } \\
87.9 \%\end{array}$ \\
$\begin{array}{l}\text { Zahra Khandan } \\
\begin{array}{l}\text { Khadem Alreza, A } \\
\text { Karimian, 2016 } \\
\text { [32] }\end{array}\end{array}$ & $\begin{array}{l}\text { Classification of Leukemic } \\
\text { Blood Image using machine } \\
\text { vision system }\end{array}$ & $\begin{array}{l}\text { Color space conversion } \\
\text { model, watershed conversion }\end{array}$ & $\begin{array}{c}\text { Accuracy } \\
93 \%\end{array}$ \\
$\begin{array}{l}\text { Ricardo J Ferrari, } \\
\begin{array}{l}\text { Bruno C Gregorio } \\
\text { da Silva, 2015 [33] }\end{array}\end{array}$ & $\begin{array}{l}\text { Intravital Video Microscopy } \\
\text { for detection of cells based on } \\
\text { the Eigenvalues analysis using }\end{array}$ & $\begin{array}{l}\text { Detection of wbcs based on } \\
\text { Hessian Matrix }\end{array}$ & $\begin{array}{c}\text { Improveme } \\
\text { nt in IVM } \\
\text { stabilization. } \\
\text { Better than TM } \\
\text { technique. }\end{array}$ \\
\hline
\end{tabular}

\section{Result and Discussion}

The proposed acute leukemia diagnostic methodology contains several phases with primary emphasis on detecting, segmenting, and then classifying acute leukemia blast cells. The PB images are first obtained as inputs to the diagnostic process and then analyzed through the proposed acute leukemia diagnostic phases. [34] The performance of the whole process is evaluated through various approaches and measures. The performance can be by using certain parameters to make certain decision of proposed framework. In the evaluation process, below some major parameters can be considered like accuracy, recall, precision, F- measure etc. The outcome of this evaluation process can be classified in (TP) True Positive, (FP) False Positive, (TN) True Negative and (FN) False Negative. In True Positive, affected leucocytes cells are identified accurately with good accuracy rate and in True Negative, non-affected leucocytes cells are identified. In False Positive, dangerous and non-affected cells are identified and in False Negative, non-dangerous but affected cells are identified.

\section{Conclusion}

In this paper, we discussed the background literature on the digital Image processing, including, color spaces, and image segmentation. An elaborative discussion regarding feature extraction was provided; this gives a clear idea about how work carried out here to accomplish the feature extraction methodology for the analysis of acute leukemia blast cells. This includes discussion of feature extraction and selection techniques including, Support Vector Machine. We additionally investigated existing arrangements of intense leukemia demonstrative frameworks which have been recently evolved to help and work with hematologists for the exact determination of the illness. This paper provided a report by the International Agency for Research on Cancer (IARC) and this shows that near about 250,000 cases of ALL and AML cancer are found and every year it diagnosed at the age of 19. Also provided Statistics by the American Cancer Society regarding the distribution of the more common childhood cancers for children from birth to 14 years old in the United States. The National Cancer Registry report published in 2008 gives categorized the most common types of cancer in Malaysia according to the gender i.e. male and female. 


\section{References}

[1] Minetto, Dorini and Leite. White blood cell segmentation using morphological operators and scale-space analysis. SIBGRAPI 07: Proceedings of the XX Brazilian Symposium on Computer Graphics and Image Processing. 2007.

[2] Deng, Liao. An accurate segmentation method for white blood cell images. IEEE International Symposium on Biomedical Imaging. 2002; 245-248.

[3] Yang L, Meer P, Foran DJ. Unsupervised segmentation based on robust estimation and color active contour models. IEEE Trans.Inf. Technol.Biomed. 9. 2005; 475-486.

[4] BM Silva, JJPC Rodrigues, I de la Torre Díez, M López-Coronado, and K Saleem. Mobile-health: A review of current state in 2015. J. Biomed. 2015; 265-272.

[5] Yi F, Chongxun Z, Chen P, Li L, White blood cell image segmentation using on-line trained neural network. In: Proceedings of 27th International Conference on Engineering in Medicine and Biology Society. 2006; 6476-6479.

[6] Yampri P, Pintavirooj C, Daochai S, Teartulakarn S. White blood cell classification based on the combination of Eigen cell and parametric feature detection. In: IEEE Conference Industrial Electronics and Applications. 2006; 1-4.

[7] Chinwaraphat S, Sanpanich A, Pintavirooj C, Sangworasil M, Tosranon P. A modified fuzzy clustering for white blood cell segmentation. In: Proceedings of the Third International of Symposium on Biomedical Engineering. 2008; 356-359.

[8] FI Sholeh. White blood cell segmentation for fresh blood smear images. Proc. Int. Conf. Adv. Computer Sci. Inf. Syst. 2013; 425-429.

[9] S Nazlibilek, D Karacor, T Ercan, MH Sazli, O Kalender and Y Ege. Automatic segmentation, counting, size determination and classification of white blood cells. 2014; 58-65.

[10] J Prinyakupt and C Pluempitiwiriyawej. Segmentation of white blood cells and comparison of cell morphology by linear and naive Bayes classifiers. Biomed. Eng. On Line. 2015; 63.

[11] S Ravikumar. Image segmentation and classification of white blood cells with the extreme learning machine and the fast relevance vector machine. Nanomed, Biotechnol. 2016; 985-989.

[12] Kothari R, Cualing $\mathrm{H}$ and Balachander T. Neural Network Analysis of Flow Cytometry Immunophenotype Data. IEEE Transactions On Biomedical Engineering. 1996; 803-810.

[13] American Cancer Society. Childhood Leukemia. Retrieved on 23/10/2018 from http://www.cancer.org/cancer/leukemiainchildren/detailedguide/childhoodleukemia-diagnosis. 2013.

[14] American Childhood Cancer Organization. Childhood Cancer Statistics. Retrieved on 19/11/2018 from http://www.acco.org/Information/AboutChildhoodCancer. 2013.

[15] NIC Marzuki, NH Mahmood and MAA Razak. Segmentation of white blood cell nucleus using active contour. 2015; 115-118.

[16] BC Ko, JW Gim and JY Nam. Automatic white blood cell segmentation using stepwise merging rules and gradient vector flow snake. Micron. 2011; 695-705.

[17] F Zamani and R Safabakhsh. An unsupervised GVF snake approach for white blood cell segmentation based on nucleus. Proc. 8th Int. Conf. Signal Process. 2006; 1453-1456.

[18] Dohner H, Estey EH, Amadori S, Appelbaum FR, Buchner T, Burnett AK, Larson RA. Diagnosis and management of acute myeloid leukemia in adults: recommendations from an international expert. 2010; 453-474.

[19] Gokbuget $\mathrm{N}$ and Hoelzer D. Treatment of adult acute lymphoblastic leukemia. Paper presented at the Seminars in hematology. 2009; 64-75.

[20] Esposito F and Malerba D. Machine Learning in Computer Vision. Applied Artificial Intelligence. Published in An International Journal. 2001; 693-705.

[21] Lai DT, Pakkanen J, Begg R and Palaniswami M. Computational Intelligence and Sensor Networks for Biomedical Systems. Encyclopedia of healthcare information systems. 2008.

[22] LB Dorini, R Minetto and NJ Leite. Semiautomatic white blood cell segmentation based on multiscale analysis. IEEE J. Biomed. Health Information. 2013; 250-256.

[23] SF Bikhet, AM Darwish, HATolba and SI Shaheen. Segmentation and classification of white blood cells. Proc. IEEE Int. Conf. Acoust., Speech, Signal Process. 2000; 2259-2261.

[24] Lim G C C, Rampal S, \& Yahaya H. Cancer Incidence in Peninsular Malaysia- The Third Report of the National Cancer Registry, Malaysia. National Cancer Registry. 2008.

[25] Nilanjan Ray. A concave cost formulation for parametric curve fitting: Detection of leukocytes from intravital microscopy images. IEEE International Conference on Image Processing. 2010.

[26] Anjali Gautam, Priyanka Singh, Balasubramanian Raman, Harvendra Bhadauria. Automatic classification of leukocytes using morphological features and Naïve Bayes classifier. IEEE Region 10 Conference. 2016. 
[27] Filip Novoselnik, Ratko Grbic, Irena Galic, Filip Doric. Automatic White Blood Cell Detection and Identification Using Convolutional Neural Network. IEEE International Conference on SST. 2018.

[28] S Dhiravida Janani, R Muthu Selvi, G Mlndhu. Blood Cell Detection and Counting Using Convolutional Sparse Dictionary Learning. IEEE International Conference on Current Trends towards Converging Technologies. 2018.

[29] Anjali Gautam, Harvindra Bhadauria. Classification of white blood cells based on morphological features. IEEE International Conference on Advances in Computing, Communications and Informatics. 2014.

[30] Muhammad Sajjad, Siraj Khan, Muhammad Shoaib, Hazrat Ali, Zahoor Jan, Khan Muhammad, Irfan Mehmood. Computer Aided System for Leukocytes Classification and Segmentation in Blood Smear Images. IEEE International Conference on Frontiers of Information Technology. 2016.

[31] Shubham Manik, Lalit Mohan Saini, Nikhil Vadera. Counting and classification of white blood cell using Artificial Neural Network. IEEE International Conference on Power Electronics, Intelligent Control and Energy Systems. 2016.

[32] Zahra Khandan Khadem Alreza, Alireza Karimian. Design a new algorithm to count white blood cells for classification Leukemic Blood Image using machine vision system. IEEE International Conference on Computer and Knowledge Engineering. 2016.

[33] Bruno C Gregorio da Silva, Ricardo J. Ferrari. Detection of Leukocytes in Intravital Video Microscopy Based on the Analysis of Hessian Matrix Eigenvalues. SIBGRAPI Conference on Graphics, Patterns and Images. 2015.

[34] S. Agaian, M. Madhukar, A. T. Chronopoulos, Automated screening system for acute myelogenous leukemia detection in blood microscopic images, IEEE Systems journal 8. 2014. 